\title{
Lymphocyte activating gene 3 protein expression in nasopharyngeal carcinoma is correlated with programmed cell death-1 and programmed cell death ligand-1, tumor-infiltrating lymphocytes
}

Fan Luo ${ }^{1 \dagger}$, Jiaxin $\mathrm{CaO}^{2 \dagger}$, Feiteng $\mathrm{Lu}^{2+}$, Kangmei Zeng ${ }^{2}$, Wenjuan $\mathrm{Ma}^{3}$, Yan Huang ${ }^{2}$, Li Zhang ${ }^{2 *}$ and Hongyun Zhao ${ }^{*}$

\begin{abstract}
Background: Immunotherapy has shown promising efficacy in patients with nasopharyngeal carcinoma (NPC). Lymphocyte activating 3 gene (LAG-3) represents a significant immune target, however, its relationship with NPC remains unclear. This study aimed to evaluate LAG-3 expression in NPC and its association with CD3+ tumor-infiltrating lymphocytes (TILs), Granzyme B (GZMB), programmed death ligand 1 (PD-L1), and programmed death 1 (PD-1) expression.

Methods: A total of 182 patients with NPC from Sun Yat-sen University Cancer Center, China, were included in this retrospective study. LAG-3 expression in 15 NPC cell lines and LAG-3, CD3+TILs, GZMB, PD-L1 and PD-1 in clinical samples were estimated using immunohistochemistry. The Chi-square test was used to estimate the association between LAG-3, other biomarkers, and clinical characteristics. Survival analysis was performed using the Kaplan-Meier method and the Cox regression model.

Results: LAG-3 was negatively expressed in all of the 15 NPC cell lines, whereas, 147 patients with NPC (80.8\%) exhibited high LAG-3 expression on TILs from tumor tissues. Male patients and those who were EBV-positive presented higher LAG-3 expression. Correlation analyses showed that LAG-3 expression was related to PD-1 expression on TILs, as well as, PD-L1 expression on tumor cells (TCS) and TILs. Both the univariate and multivariate Cox models indicated that pathological type III $(P=0.036)$, higher LAG-3 on TILs $(P<0.001)$, higher PD-L1 on TCs $(P=0.027)$, and higher PD-1
\end{abstract}

\footnotetext{
*Correspondence: zhangli6@mail.sysu.edu.cn; zhaohy@sysucc.org.cn

${ }^{\dagger}$ Fan Luo, Jiaxin Cao and Feiteng Lu contributed equally to this work

${ }^{2}$ Department of Medical Oncology, State Key Laboratory of Oncology

in South China, Collaborative Innovation Center for Cancer Medicine,

Sun Yat-Sen University Cancer Center, 651 Dongfeng Road East,

Guangzhou 510060, Guangdong, China

${ }^{4}$ Department of Clinical Research, State Key Laboratory of Oncology

in South China, Collaborative Innovation Center for Cancer Medicine,

Sun Yat-Sen University Cancer Center, 651 Dongfeng Road East,

Guangzhou 510060, Guangdong, China

Full list of author information is available at the end of the article
}

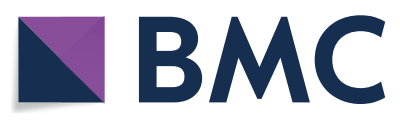

(c) The Author(s) 2021. Open Access This article is licensed under a Creative Commons Attribution 4.0 International License, which permits use, sharing, adaptation, distribution and reproduction in any medium or format, as long as you give appropriate credit to the original author(s) and the source, provide a link to the Creative Commons licence, and indicate if changes were made. The images or other third party material in this article are included in the article's Creative Commons licence, unless indicated otherwise in a credit line to the material. If material is not included in the article's Creative Commons licence and your intended use is not permitted by statutory regulation or exceeds the permitted use, you will need to obtain permission directly from the copyright holder. To view a copy of this licence, visit http://creativecommons.org/licenses/by/4.0/. The Creative Commons Public Domain Dedication waiver (http://creativeco mmons.org/publicdomain/zero/1.0/) applies to the data made available in this article, unless otherwise stated in a credit line to the data. 
on TILs $(P<0.001)$ were associated with poorer disease-free survival (DFS). However, lower PD-L1 expression on TILs was related to superior DFS only in the univariate Cox analyses $(P=0.002)$.

Conclusion: Higher LAG-3 and PD-1 on TILs, and higher PD-L1 expression on TCS, and pathological type III were identified as independent risk factors for poorer DFS in NPC patients. Our data demonstrate that LAG-3 is a promising inhibitory receptor that may play an important role in anti-NPC therapy.

Keywords: LAG-3, CD3, GZMB, PD-L1, PD-1, NPC

\section{Background}

Nasopharyngeal carcinoma (NPC) is a common malignancy of the upper or side wall of the nasopharyngeal chamber. Somewhat unexplainably, NPC has distinct disparities in its geographical distribution, with a particularly high occurrence in Guangdong province, China [1]. NPC is closely related to the Epstein-Barr virus (EBV), with the EBV proven as its main etiologic cause [2]. With recent developments in radiotherapy and combined chemoradiotherapy, the survival of NPC patients has been substantially prolonged $[3,4]$. Despite advances in treatment, local relapse and distant metastasis continue to represent major causes of cancer progression following anti-NPC therapy [5]. Due to limited advances made regarding chemotherapy regimens, it is critical to explore novel approaches for the treatment of metastatic NPC that alleviate toxicity and promote survival benefits.

Immune checkpoints expressed on tumor cells and immune cells play a crucial role in inhibiting or enhancing anti-tumor immunity. Blocking immune checkpoints has become a promising anti-neoplastic strategy $[6,7]$. Recently, immunotherapeutic strategies targeting programmed cell death-1 (PD-1), and programmed cell death ligand-1 (PD-L1) checkpoints have been associated with a remarkable anti-tumor response among various solid tumors [8]. An increasing number of clinical trials involving immunotherapy have shown promising outcomes for NPC patients [6, 9]. PD-L1 has been shown to adjust type $1 \mathrm{~T}$ helper (Th1) autoimmune reactions, and is expressed on both tumor cells (TCs) and tumorinfiltrating lymphocytes (TILs) [10]. PD-L1 promotes tumor cell apoptosis by activating PD-1 expressed on T lymphocytes [11]. PD-1 is a suppressive receptor located on activated $\mathrm{T}$ lymphocytes that regulates immunological suppression and immune escape [12]. Inhibiting PD-1 or PD-L1 signaling is a potential therapeutic strategy to strengthen the immune response towards tumor cells. Numerous promising predictive biomarkers for immunotherapy have been suggested for various cancer types, including PD-L1 [13, 14], TILs [15], level of microsatellite instability (MSI) [16], and tumor mutational burden (TMB) [17].

Recently, anti-PD-1 and PD-L1 treatments have been associated with potential clinical effects in some NPC patients [18-22]. However, other related studies have found that immuno-monotherapy was ineffective in NPC patients. For instance, a phase I study showed that the overall response of patients with advanced NPC treated with camrelizumab therapy was $34 \%$ (95\% CI 24-44) and the median progression-free survival (PFS) was only 5.6 months (95\% CI 3.3-7.9) [23]. Another study reported that the median PFS of pembrolizumab monotherapy was only 3.7 months, (95\% CI $2.1-13.4)$ and only 2.8 months (95\% CI 1.8-7.4) following treatment with nivolumab monotherapy as palliative treatment for NPC $[6,24]$. It has also been reported that only $25 \%$ of NPC patients will benefit from anti-PD-1/PD-L1 immunotherapy, highlighting the critical need for further research into novel therapeutic regimens [25].

Lymphocyte activating gene 3 (LAG-3, also termed CD223), is a $51-K D$ transmembrane protein and a member of the immune globulin superfamily [26]. It represents another potential therapeutic target. It is mainly expressed on natural killer cells [26], B cells [27], TILs [28], and dendritic cells [29, 30]. LAG-3 was first identified in the 1990s, its structure is similar to CD4 as both have four extracellular domains [26]. The LAG-3 gene is located near the CD4 gene on chromosome 12, and about $20 \%$ of the amino acid sequence of LAG-3 and CD4 are identical. Hence, LAG-3 acts as a ligand to bind to the major histocompatibility complex (MHC) class II, and possesses an even higher affinity than CD4 [31-33]. Pre-clinical studies indicate that LAG-3 inhibition activates the effector capabilities of $\mathrm{T}$ cells and synergizes with other immune checkpoint inhibitors (i.e., antiPD-1/PD-L1) [34-38], which provides a strong rationale for simultaneously targeting LAG-3 and PD-1/PD-L1 to enhance anti-tumor $\mathrm{T}$ cell immunity. The upregulation of LAG-3 in TILs and in MHC II+tumors that are resistant to anti-PD-1 antibodies supports this idea [39]. An increasing number of basic and clinical studies have begun to adopt a LAG-3 blockade strategy. As of March 2021, 14 anti-cancer drugs target LAG-3 (data source: https://www.clinicaltrials.gov). Moreover, a number of pharmaceutical companies in China have distributed LAG-3 fusion proteins, antibodies, and bispecific antibodies targeting LAG-3 and other immune checkpoints. These companies have also applied for clinical 
applications to enhance the efficacy of immunotherapy (data source: https://www.cde.org.cn/). A previous study indicated that LAG-3 expression is closely related to a worse survival of patients with non-small cell lung cancer (NSCLC) [25]. Conversely, several studies indicate that LAG-3 expression is related to a better survival for gastric cancer [40] and breast cancer patients [41]. However, it remains unclear whether LAG-3 has a significant influence on the prognosis of NPC patients.

It has been reported that LAG-3 can induce T cell dysfunction in the tumor microenvironment (TME) [42-44]. Previous studies have shown that the TME interaction with LAG-3 on TILs can modulate an anti-cancer immunoreaction [45]. The extent of TILs infiltration in the TME is related to the treatment effects of PD-1/PD-L1 inhibition $[18,46]$. A recent study indicated that lower CD3+ TIL infiltration was related to a poorer DFS for NPC patients [47]. It is well established that the immune system can eradicate infected or transformed cells, which is largely mediated through the activities of natural killer (NK) and cytotoxic T lymphocyte (CTL) cells [48]. The main mechanism of cellular apoptosis induced by NK cells, and CTLs is through the release of the granzyme B protein (GZMB) [49]. GZMB is localized inside endosomes as a zymogen and is subsequently activated by cathepsins to produce the fully active form of GZMB [50]. A meta-analysis found that GZMB+lymphocytes were significantly associated with a better overall survival (OS) for patients with hepatocellular carcinoma (HCC) [51] and colorectal cancer [52]. However, the clinical relevance of PD-1, TILs, GZMB, PD-L1, and LAG-3 in patients with NPC remains unclear.

Here, we explore the association between LAG-3 expression and clinical characteristics at the cellular level and in tumor samples from NPC patients. We also evaluate the relationship between PD-1, GZMB, CD3+ TILs, PD-L1 expression and the prognosis of NPC patients.

\section{Methods \\ Patients}

This retrospective study included 182 patients who were pathologically diagnosed with NPC between January 1, 2006 and December 30, 2018 at Sun Yat-sen University Cancer Center (SYSUCC), China. Malignancy stages were determined according to the tumor node metastasis (TNM) staging method (eighth version) of the American Joint Committee on Cancer (AJCC). Qualified patients were 18-80 years of age with pathologically diagnosed NPC, no second primary cancer, and no distant metastases. We collected patient information regarding age, gender, smoking history, EBV status, family history, TNM stage, pathologic types, and treatment.

\section{Cell lines}

A tissue microarray (TMA) (2 mm) involving $15 \mathrm{NPC}$ cell lines was generated in the laboratory, and all specimens were evaluated in triplicate. Cells were collected, settled for one night, compounded with $0.9 \%$ Sepharose, and allowed to curdle at room temperature for at least $5 \mathrm{~min}$. Each solidified agar pellet was lightly positioned in a cassette and placed in $70 \%$ alcohol. The solidified agar pellets were disposed of and implanted in paraffin blocks. The cores were then taken from each encased block to produce the TMA, from which 4-mm sections were sliced.

\section{Immunohistochemical analysis for LAG-3, CD3, GZMB, PD-L1, and PD-1 expression}

Pathologically identified, formalin fixed, paraffin-embedded NPC specimens from patients who were biopsied at SYSUCC were retrospectively tested. Archived hematoxylin-eosin staining sections were assessed by two independent pathologists. Immunohistochemical (IHC) staining for LAG-3, CD3, GZMB, PD-L1, and PD-1 expression was conducted using sections obtained from the formalin-fixed diagnostic specimens. Briefly, 4- $\mu \mathrm{m}$ sections were deparaffinized in xylene, rehydrated, and then treated with a citrate antigen restore buffer $(\mathrm{pH} 9.0)$ to expose the antigen in the sections. After processing following the conventional steps, the slides were incubated overnight at $4{ }^{\circ} \mathrm{C}$ with primary antibodies against LAG-3 (1:200, ab101500, Abcam, Cambridge, MA), CD3 (1:200, ab16669, Abcam, Cambridge, MA), GZMB (1:100, ab255598, Abcam, Cambridge, MA), PD-L1 (M365329, Dako, Carpenteria, CA), and PD-1 (1:50, 315M, Cell Marque, Rocklin, CA). After washing them three times with a phosphate-buffered saline (PBS), 5 min per wash, the sections were sequentially incubated with a Horseradish peroxidase (HRP)-conjugated goat anti-human secondary antibody (PV6000, ZSGB-BIO, Beijing, China). An evaluation was performed using 3, 3'-Diaminobenzidine (DAB) substrate kits (ZLI-9017, ZSGB-BIO, Beijing, China). The sections were stained with hematoxylin for $4 \mathrm{~min}$ and counterstained with bluing reagent for $4 \mathrm{~min}$. The slides were washed and then dehydrated in $70 \%$ to $100 \%$ alcohol baths followed by xylene baths before coverslip application.

\section{Pathological evaluation of LAG-3, CD3+TILs, GZMB, and PD-1/PD-L1 expression}

The evaluation of LAG-3, CD3+ TILs, and GZMB, PD-1, and PD-L1 expression in the smears were performed by two pathologists who were blinded to the results of the whole tumor sections. Five randomly selected highpower sites $(400 \times)$ in every sample were chosen to estimate the number of positive cells. The expression of 
LAG-3, PD-1, GZMB, and CD3+ TILs was assessed in the tumor stroma only, and PD-L1 staining was assessed in both the tumor and stromal cells [53].

\section{Confirmation of the LAG-3, GZMB, CD3, PD-1, and PD-L1 expression cut-off using $\mathrm{X}$-tile}

The expression score of PD-L1 on TCs was determined by multiplying the intensity and density. The intensity of PD-L1 expression on TCs was scored as 0 (negative), 1 (weak), 2 (moderate), or 3 (strong). The density of PD-L1 expression on TCs was scored as 0 (negative), $1(0-1 \%)$, $2(2-10 \%), 3(11-50 \%)$, or $4(>50 \%)$ [54]. The density of PD-L1 expression on TILs was scored as $0(<5 \%), 1$ (5-25\%), 2 (26-50\%), 3 (51-75\%), or 4 (>75\%) [55]. We used X-tile Software (Yale University, New Haven, CT, USA) to evaluate the most suitable cut-off values for LAG-3, GZMB, CD3, PD-1, and PD-L1 and the optimal values for predicting DFS. X-tile Software provides a precise statistical estimation by distributing all cases into two groups based on the "low" or "high" expression of a particular biomarker [56].

\section{Follow-up}

Patients were followed up every 3 months for the first 3 years, and every 6 months over the next 2 years, and finally once each year thereafter. A semiannual follow-up was conducted until the end of the study or the death of the patient, whichever occurred first. The last follow-up time for all living patients was October 2020.

\section{Statistical analysis}

The statistical analyses were conducted using SPSS version 22 (IBM, Armonk, NY, USA) and GraphPad Prism 8 (GraphPad Software, La Jolla, CA, USA). Optimal cut-off values for the biomarkers were obtained using X-tile Software. Chi-square tests and Fisher's exact tests were used to estimate the relationship between LAG-3 and clinical characteristics, CD3, GZMB, PD-L1, and PD-1. The odds ratios (ORs) for LAG-3 expression were estimated for the variables: age, EBV status, family history, gender, smoking status, pathological pattern, TNM staging, CD3, GZMB, PD-L1, and PD-1. Survival was evaluated using the Kaplan-Meier approach. A Cox regression analysis was used to explore the correlation between the clinicopathological variables, the above biomarkers, and DFS. A $P$-value less than 0.15 in the univariate analysis was used to screen the values eligible for the multivariate analysis with the Cox proportional hazard model, together with 95\% confidence intervals (CI). A $P<0.05$ for all statistics was considered significant.

\section{Results}

\section{LAG-3 expression in NPC cell lines}

The hematoxylin-eosin (HE) staining results for 15 NPC cell lines (NP69, CNE1, HNE1, HK-1, HONE-1, SUNE1, 6-10B, 5-8F, S18, S26, C666-1, CNE2, CNE2-EBV, TW03, and TW03-EBV) are summarized in Additional file 1: Figure S1. The expression of LAG-3 was not examined in all of the 15 NPC cell lines (Fig. 1).

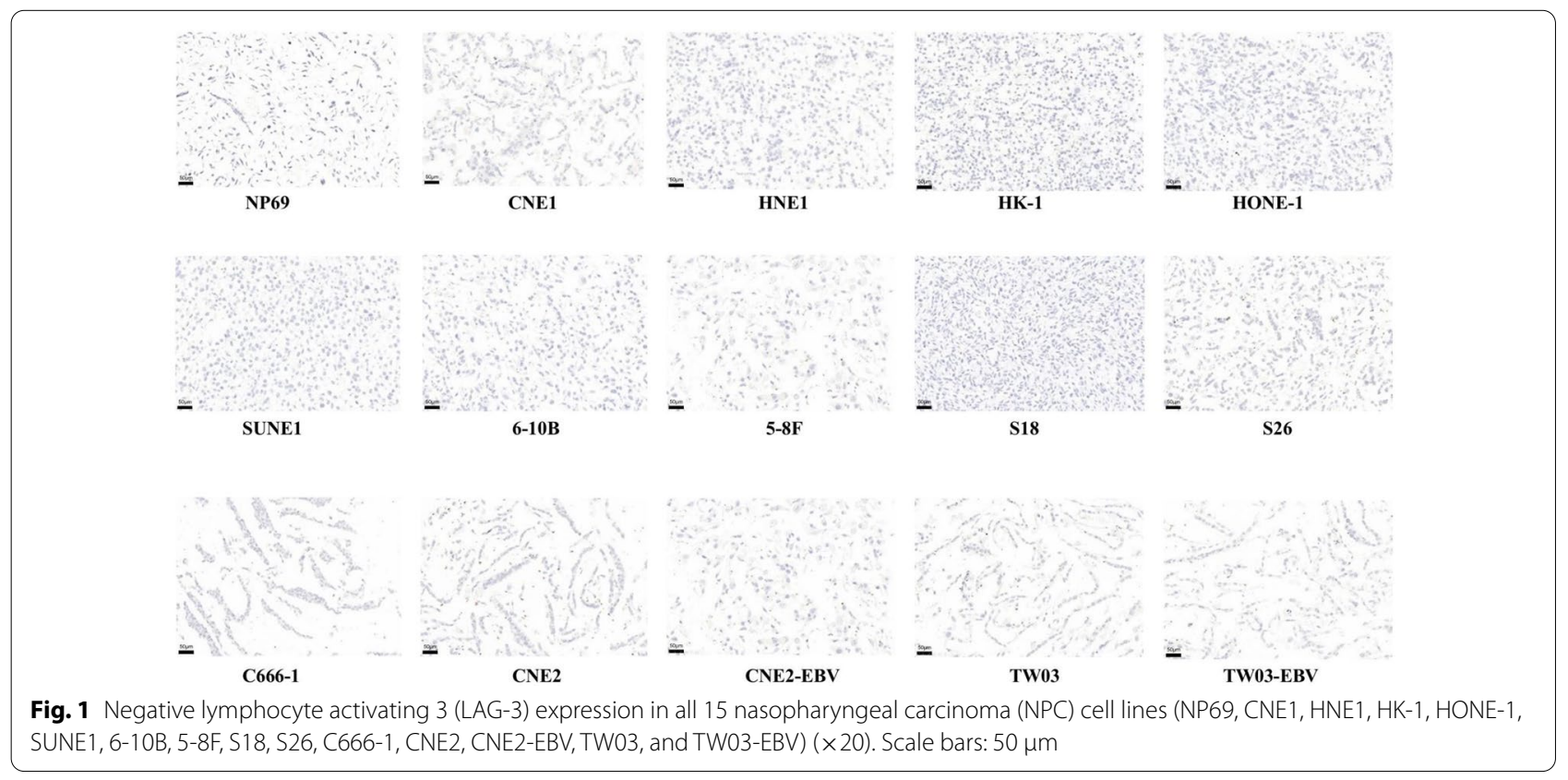




\section{Patient clinical characteristics}

In this study, 297 patients originally diagnosed with NPC at SYSUCC were screened for eligibility, 115 patients did not meet the inclusion criteria, of which 50 patients had no tumor staging or pathological type, four patients had other primary tumors, and 16 patients were lost to follow-up, and 45 patients had insufficient paraffin sections. Therefore, 182 NPC patients were evaluated using a series of screening steps (Fig. 2). The median followup time was 23.2 months in this patient population, and $50(27.5 \%)$ patients were females and $132(72.5 \%)$ were males. A total of 115 (63.2\%) patients were EBV positive, 67 (36.8\%) were EBV-negative. The patients' age ranged from 24 to 76 years old, with a median age of 49 years old. A total of 26 (14.3\%) patients had a family history of NPC. Most patients were pathological type III (69.8\%), only $14(7.7 \%)$ and $41(22.5 \%)$ patients were pathological type I and II, respectively. There were 31 (17\%) smokers and $151(83 \%)$ nonsmokers. The cancer stages were as follows: stage I, nine (4.9\%); stage II, 35 (19.2\%); stage III, 96 (52.7\%); and stage IV, 42 (23.2\%). Forty (22\%) patients were treated with induction chemotherapy, $11(6 \%)$ with radiotherapy, and 130 (71.4\%) with radiochemotherapy (Table 1).

\section{Evaluation of all biomarkers using X-tile}

The optimal cut-off values for LAG-3 on TILs, PD-L1 on TCs, and PD-1 expression on TILs obtained using X-tile were 14 cells (Fig. 3A, B), 9 (Fig. 3D, E), and 2 cells (Fig. 3G, H), respectively. Higher expression of LAG-3 and PD-1 on TILs as well as PD-L1 expression on TCs were associated with shorter a DFS compared with those with a lower expression than their respective cut-off values (Fig. 3C, F, I). However, the appropriate cut-off values for GZMB, CD3, and PD-L1 expression on TILs obtained by X-tile were unassociated with obvious statistical differences, and consisted of 112 cells, 215 cells, and 1\%, respectively (Table 4).

\section{Expression of LAG-3, CD3, GZMB and PD-1, and PD-L1} in NPC and their correlation with clinical characteristics IHC staining demonstrated low and high expression of LAG-3 (Fig. 4A), PD-1 (Fig. 4B), PD-L1 (Fig. 4C), CD3 (Fig. 4E) in the cell membranes and GZMB in the

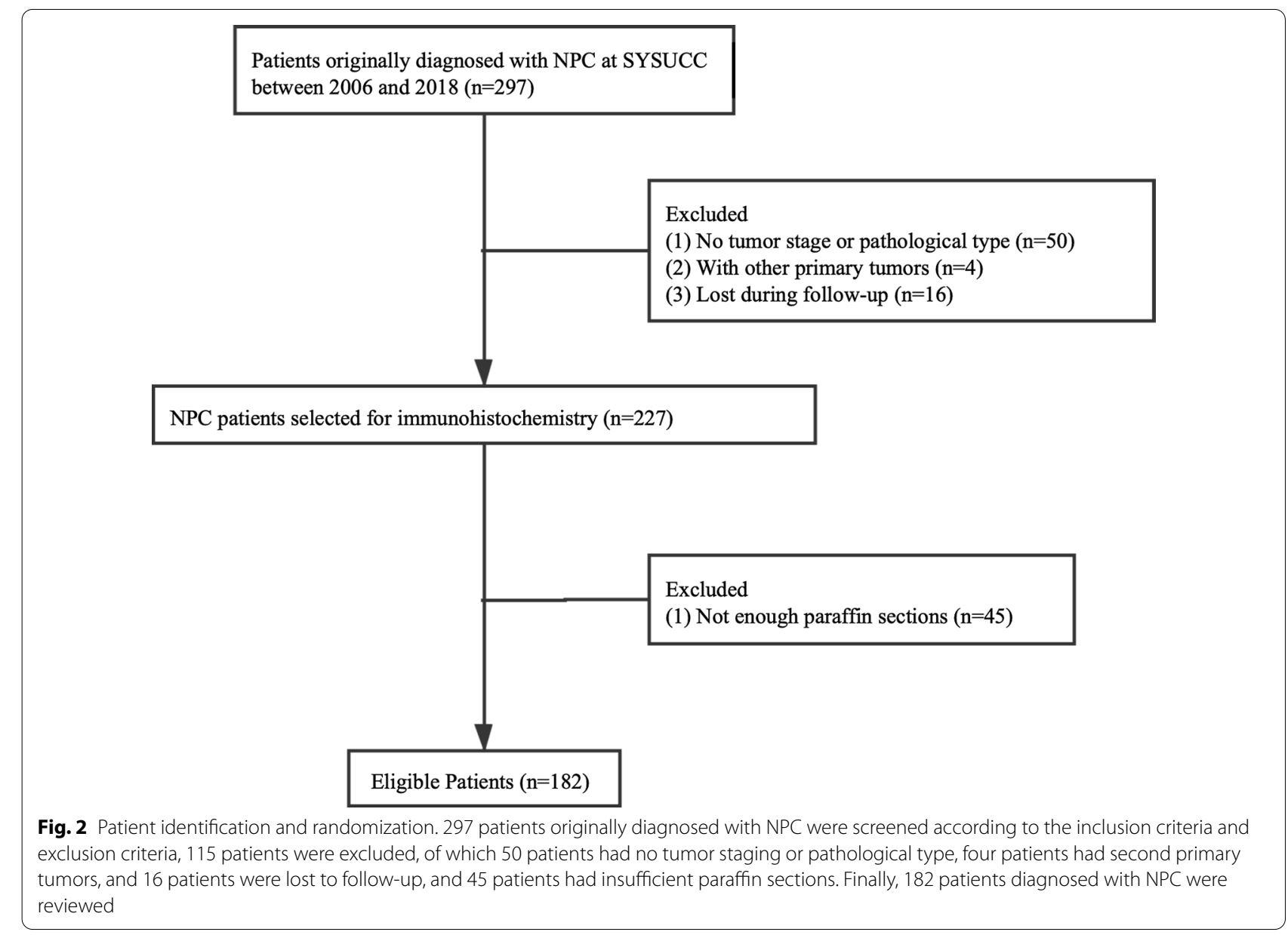


Table 1 Characteristics of all patients $(n=182)(100 \%)$

\begin{tabular}{|c|c|c|}
\hline Characteristics & Cases $(n=182)$ & Percentage (\%) \\
\hline \multicolumn{3}{|l|}{ Age (years) } \\
\hline Median (range) & $49(24-76)$ & \\
\hline$<60$ & 156 & 85.7 \\
\hline$\geq 60$ & 26 & 14.3 \\
\hline \multicolumn{3}{|l|}{ Gender } \\
\hline Male & 132 & 72.5 \\
\hline Female & 50 & 27.5 \\
\hline \multicolumn{3}{|l|}{ Smoking status } \\
\hline Non-smoker & 151 & 83 \\
\hline Smoker & 31 & 17 \\
\hline \multicolumn{3}{|l|}{ EBV status } \\
\hline Positive & 115 & 63.2 \\
\hline Negative & 67 & 36.8 \\
\hline \multicolumn{3}{|l|}{ Family history } \\
\hline Yes & 26 & 14.3 \\
\hline No & 156 & 85.7 \\
\hline \multicolumn{3}{|l|}{ Pathological type } \\
\hline I & 14 & 7.7 \\
\hline ॥ & 41 & 22.5 \\
\hline III & 127 & 69.8 \\
\hline \multicolumn{3}{|l|}{ T-stage } \\
\hline $\mathrm{T} 1$ & 24 & 13.2 \\
\hline $\mathrm{T} 2$ & 53 & 29.1 \\
\hline T3 & 72 & 39.6 \\
\hline $\mathrm{T} 4$ & 33 & 18.1 \\
\hline \multicolumn{3}{|l|}{$\mathrm{N}$-stage } \\
\hline No & 34 & 18.7 \\
\hline $\mathrm{N} 1$ & 60 & 33 \\
\hline N2 & 76 & 41.8 \\
\hline N3 & 12 & 6.5 \\
\hline \multicolumn{3}{|l|}{ M-stage } \\
\hline MO & 178 & 97.8 \\
\hline M1 & 4 & 2.2 \\
\hline \multicolumn{3}{|l|}{ Disease stage } \\
\hline I & 9 & 4.9 \\
\hline$\|$ & 35 & 19.2 \\
\hline III & 96 & 52.7 \\
\hline IV & 42 & 23.2 \\
\hline \multicolumn{3}{|l|}{ DFS (months) } \\
\hline Median (range) & $23.2(4.6-156.3)$ & \\
\hline \multicolumn{3}{|l|}{ Treatment } \\
\hline Induction chemotherapy & 40 & 22 \\
\hline Radiotherapy & 11 & 6 \\
\hline Radiochemotherapy & 130 & 71.4 \\
\hline Chemotherapy & 1 & 0.6 \\
\hline
\end{tabular}

DFS: disease-free survival cytoplasm (Fig. 4D). LAG-3 expression was high in 147 $(80.8 \%)$ patients. There were $90(49.5 \%)$ patients who exhibited high PD-1 expression and 154 (84.6\%) patients with high PD-L1 expression on TILs. Thirty-nine (21.4\%) patients had high PD-L1 expression on TCs. Further evaluation of TILs found that 125 (68.7\%) patients had high CD3 expression, and $44(24.2 \%)$ patients had high GZMB expression (Table 2). Male patients $\left(\chi^{2}=5.147\right.$, $\mathrm{OR}=2.400,95 \%$ CI $1.112-5.181, P=0.023)$ with a positive-EBV status $\left(X^{2}=15.560\right.$, OR $=4.487,95 \%$ CI $2.052-$ 9.809, $P<0.001)$ presented higher LAG-3 expression (Table 3).

\section{Correlation between LAG-3 expression and other immune checkpoints}

A close relationship was observed among LAG-3, PD-1, and PD-L1 expression. We also conducted a relativity analysis between LAG-3, GZMB, and CD3 TILs. High LAG-3 expression was significantly related to high PD-1 expression on TILs $\left(x^{2}=5.630, \mathrm{OR}=2.535,95 \%\right.$ CI $1.157-5.551, P=0.018)$, PD-L1 on TCs $\left(\chi^{2}=8.877\right.$, $\mathrm{OR}=0.307,95 \%$ CI $0.138-0.685, P=0.003)$, and PD-L1 on TILs $\left(x^{2}=8.569, \mathrm{OR}=3.505,95 \%\right.$ CI $1.462-8.404$, $P=0.003)$. However, the same correlation was not observed between LAG-3 and CD3+TILs $(P=0.101)$, or $\operatorname{GZMB}(P=0.128)$ expression (Table 4$)$.

\section{Logistic regression model analysis to predict LAG-3 expression}

The calculated ORs for LAG-3 expression were 2.535 (95\% CI 1.157-5.551) and 0.513 (95\% CI $0.225-1.170)$ when low PD-1 expression was compared with high PD-1 expression on TILs and low PD-L1 expression was compared with high PD-L1 expression on TILs in the logistic regression model univariate analysis. The calculated ORs for LAG-3 expression were 0.271 (95\% CI 0.105-0.695) and 3.439 (95\% CI 1.280-9.237) when low PD-L1 expression on TCs was compared with high expression, and low PD-L1 expression on TILs was compared with high expression in the logistic regression model multivariate analysis (Table 5).

\section{The impact of LAG-3 and other checkpoints on DFS}

We found that lower LAG-3, PD-1, and PD-L1 expression was associated with a more favorable survival prognosis. The Kaplan-Meier analysis estimated that higher LAG-3 expression on TILs (19.7 months [95\% CI 18.124] versus 36.4 months [95\% CI 26.7-44.3], $p<0.001$ ) (Fig. 5A), PD-1 expression on TILs (18.45 months [95\% CI 16.65-20.44] versus 26.55 months [95\% CI 24.334.6], $p<0.001$ ) (Fig. 5B), and PD-L1 expression on TCs (17.15 months [95\% CI 13.15-19.4] versus 24.3 months [95\% CI 20.7-24.9], $p=0.027$ ) (Fig. 5C), as well as, PD-L1 


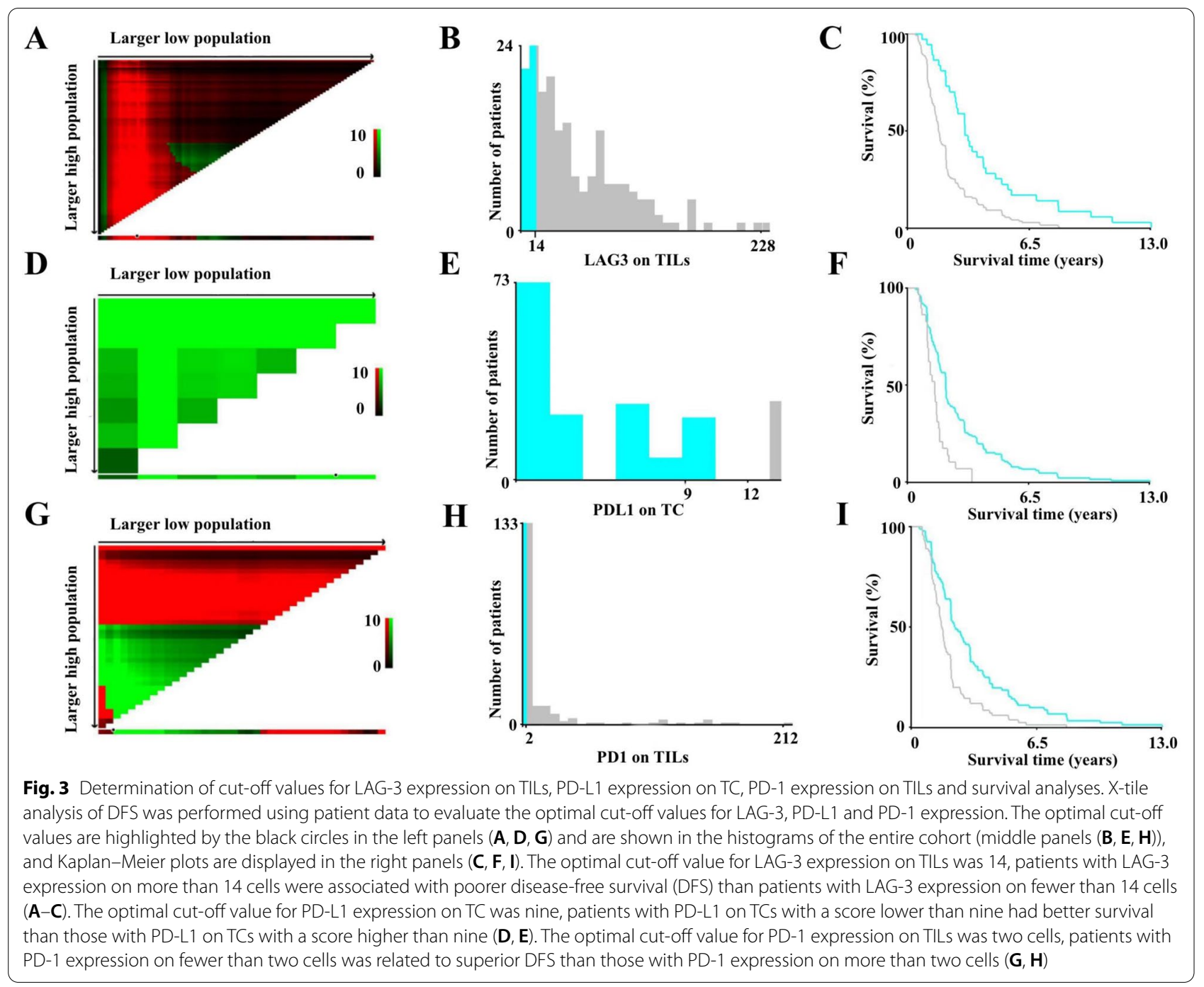

expression on TILs (20.3 months [95\% CI 18.3-24.2] versus 36.2 months [95\% CI 24.3-44.3], $p=0.002$ ) (Fig. 5D) were associated with a distinctly shorter DFS compared with those with lower expression than their respective cut-off values. We also observed that patients with lower LAG-3 and lower PD-L1 on TILs had a longer DFS than patients who had higher PD-L1 on TILs or LAG-3 or both higher PD-L1 on TILs and LAG-3 (41.2 months [95\% CI 36.4-60.3] versus 21.1 months [95\% CI 19.324.3] versus 17.2 months [95\% CI 13.1-20.3], $p<0.001$ ) (Fig. 5E). Patients with both lower LAG-3 and lower PD-1 on TILs had a longer DFS than patients who had either higher PD-1 or LAG-3 or higher PD-1 and LAG-3 (38.9 months [95\% CI 26.7-56.2] versus 24.5 months [95\% CI 20.1-30.6] versus 18.1 months [95\% CI 15.219.7], $p<0.001$ ) (Fig. 5F). Patients with both lower LAG-3 and lower PD-L1 on TCs had a longer DFS than patients who had either a higher PD-L1 on TCs or LAG-3 or higher PD-L1 on TCs and LAG-3 (36.6 months [95\% CI 24.3-56.2] versus 36.25 months [95\% CI 24.35-44] versus 19.3 months [95\% CI 17.2-22.3], $p<0.001$ ) (Fig. 5G).

\section{Cox regression analysis for DFS}

All univariate and multivariate analyses of prognostic factors are summarized in Table 6. The univariate analysis results indicated that the relevant risk factors for survival were age ( $\geq 60$ vs. $<60$ y, HR, 95\% CI 1.00 (ref.) vs 1.588 (1.024-2.462), $P=0.039)$, pathological type (III vs. III, HR, 95\% CI 1.00 (ref.) vs 0.696 (0.495-0.977), $P=0.036$ ), LAG-3 expression on TILs (Low vs. High, HR, 95\% CI 1.00 (ref.) vs 0.441 (0.296-0.657), $P<0.001)$, PD-1 expression on TILs (Low vs. High, HR, 95\% CI 1.00 (ref.) vs 0.494 (0.363-0.671), $P<0.001)$, PD-L1 expression on TCs (Low vs. High, HR, 95\% CI 1.00 (ref.) vs 0.659 (0.455-0.953), $P=0.027$ ), and PD-L1 expression on TILs 

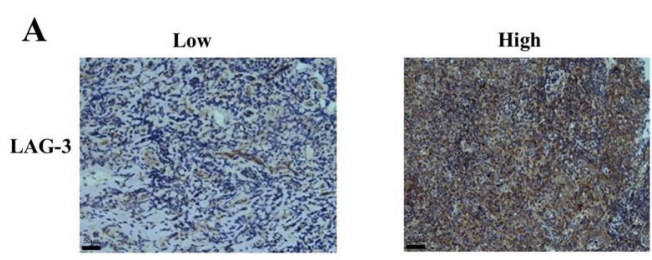

C

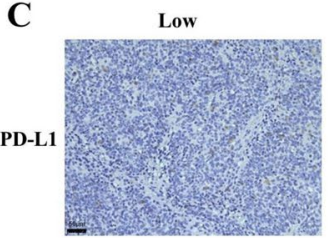

$\mathbf{E}$

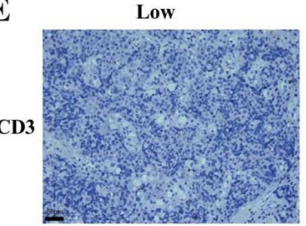

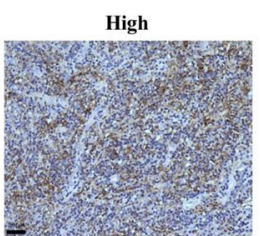

High
B

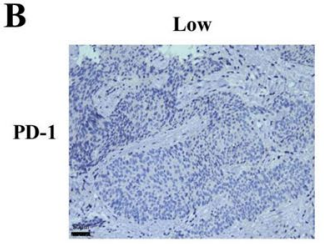

D

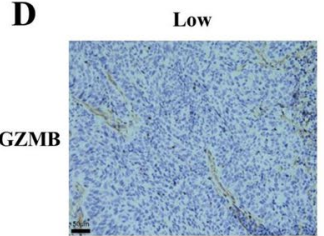

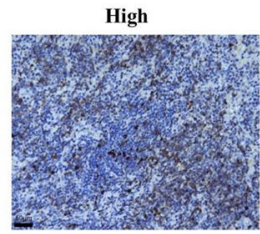

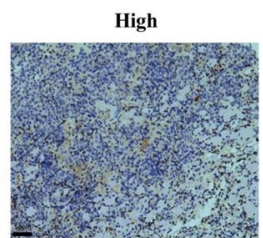

Fig. 4 Positive immunohistochemical staining for LAG-3, PD-1, PD-L1, GZMB, and CD3 expression in NPC patients ( $\times 20$ ). IHC staining demonstrated low and high expression of LAG-3 (A), PD-1 (B), PD-L1 (C), CD3 (E) in the cell membranes and GZMB in the cytoplasm (D). Brown staining represents positive cell expression, the number of positive stained cells was manually counted in the formalin fixed paraffin-embedded tissue area (i.e., each $4-\mu \mathrm{m}$ section). Five randomly selected high-power sites ( $\times 400)$ in every sample were chosen to estimate the number of positive cells. Scale bars: $50 \mu \mathrm{m}$

Table 2 Expression of LAG-3, PD-1, and PD-L1, CD3, GZMB in NSCLC patients

\begin{tabular}{lcc}
\hline Characteristics & Cases $(\mathbf{n}=\mathbf{1 8 2})$ & Percentage (\%) \\
\hline LAG-3 expression on TILs & 147 & 80.8 \\
High & 35 & 19.2 \\
Low & \\
PD-1 expression on TILs & 90 & 49.5 \\
High & 92 & 50.5 \\
Low & & \\
PD-L1 expression on TC & 39 & 21.4 \\
High & 143 & 78.6 \\
Low & & \\
PD-L1 expression on TILs & 154 & 84.6 \\
High & 28 & 15.4 \\
Low & & \\
CD3+TIL & 125 & 68.7 \\
High & 57 & 31.3 \\
Low & & 24.2 \\
GZMB & 44 & 75.8 \\
High & 138 & \\
Low & & \\
\hline
\end{tabular}

LAG-3: lymphocyte activating 3; PD-L1: programmed death ligand 1; PD-1: programmed death 1; TIL: tumor-infiltrating lymphocyte; TC: tumor cell; GZMB: granzyme B; NSCLC: non-small cell lung cancer
(Low vs. High, HR, 95\% CI 1.00 (ref.) vs 0.678 (0.4521.017), $P=0.002$ ).

The multivariate Cox analysis revealed that the independent risk factors for survival were pathological type (I-II vs. III, HR, 95\% CI 1.00 (ref.) vs 0.693 (0.484-0.992), $P=0.045$ ), LAG- 3 expression on TILs (Low vs. High, HR, 95\% CI 1.00 (ref.) vs 0.434 (0.284-0.663), $P<0.001)$, PD-1 expression on TILs (Low vs. High, HR, 95\% CI 1.00 (ref.) vs $0.558(0.400-0.778), P=0.001)$, and PD-L1 expression on TCs (Low vs. High, HR, 95\% CI 1.00 (ref.) vs 0.636 (0.432-0.937), $P=0.022)$.

\section{Discussion}

LAG-3 represents a promising immune checkpoint inhibitor and has been investigated as a target for the treatment of solid tumors in many studies [57]. One study found that LAG-3 suppresses antitumor immunity in Hodgkin's lymphoma [58]. Anti-LAG-3 treatment was also found to restrict breast carcinoma growth in an animal model [35]. Moreover, simultaneously inhibiting LAG-3 and PD-1 signaling can strengthen the T lymphocyte response in ovarian carcinoma [59]. An increasing number of basic research and clinical studies have begun to adopt a LAG-3 blockade strategy in the treatment of solid tumors [60, 61]. However, data regarding LAG-3 expression in NPC and its correlation with TILs, GZMB, PD-1, and PD-L1 remains unclear in NPC patients. 
Table 3 Relationships between LAG-3 and clinical data

\begin{tabular}{|c|c|c|c|}
\hline \multirow[t]{2}{*}{ Characteristic } & \multicolumn{3}{|c|}{ LAG-3 expression on TILs } \\
\hline & $\leq 14$ & $>14$ & $p$ value \\
\hline \multicolumn{4}{|l|}{ Age, n (\%) } \\
\hline$<60$ & $27(14.8)$ & $128(70.3)$ & 0.137 \\
\hline$\geq 60$ & $8(4.5)$ & $19(10.4)$ & \\
\hline \multicolumn{4}{|l|}{ Gender, n (\%) } \\
\hline Female & $15(8.2)$ & $35(19.2)$ & 0.023 \\
\hline Male & $20(11)$ & $112(61.6)$ & \\
\hline \multicolumn{4}{|l|}{ Smoking status, n (\%) } \\
\hline Non-smoker & $27(14.8)$ & $124(68.1)$ & 0.308 \\
\hline Smoker & $8(4.4)$ & $23(12.7)$ & \\
\hline \multicolumn{4}{|l|}{ Disease stage, $n(\%)$} \\
\hline Stage I-II & $7(3.8)$ & $37(20.3)$ & 0.521 \\
\hline Stage III-IV & $28(15.5)$ & $110(60.4)$ & \\
\hline \multicolumn{4}{|l|}{ Pathological type, n (\%) } \\
\hline$|-| \mid$ & $8(4.4)$ & $47(25.8)$ & 0.291 \\
\hline III & $27(14.9)$ & $100(54.9)$ & \\
\hline \multicolumn{4}{|l|}{ EBV status, n (\%) } \\
\hline Negative & $23(7.1)$ & $44(29.7)$ & $<0.001$ \\
\hline Positive & $12(12.1)$ & $103(51.1)$ & \\
\hline \multicolumn{4}{|l|}{ Family history, n (\%) } \\
\hline Yes & $8(4.4)$ & $18(9.9)$ & 0.107 \\
\hline No & $27(14.8)$ & $129(70.9)$ & \\
\hline \multicolumn{4}{|l|}{ Treatment, n (\%) } \\
\hline Induction chemotherapy & $5(2.7)$ & $35(19.2)$ & 0.213 \\
\hline Radiotherapy & $3(1.6)$ & $8(4.5)$ & \\
\hline Radiochemotherapy & $26(14.3)$ & $104(57.2)$ & \\
\hline Chemotherapy & $1(0.5)$ & $0(0)$ & \\
\hline
\end{tabular}

All the $p$ values marked in bold are less than 0.05 , which is statistically significant LAG-3: lymphocyte activating 3; TIL: tumor-infiltrating lymphocyte; EBV: EpsteinBarr virus

A limited number of studies have investigated LAG-3 expression in NPC and its relationship with TILs, PD-1, PD-L1, and GZMB. In our study, we first examined LAG-3 expression in NPC cell lines as well as clinical specimens and found that LAG-3 was negatively expressed on NPC cell lines regardless of EBV status, but that it was highly expressed on TILs in NPC cancer specimens. Male patients and those who were EBV-positive displayed higher LAG-3 expression. We also discovered that LAG-3 was closely related to PD-1 and PD-L1 expression. A survival analysis demonstrated that NPC patients with lower LAG-3, PD-1, and PD-L1 expression had a longer DFS. Importantly, higher LAG-3, PD-1, and PD-L1 expression on TCs, and pathological type III were confirmed to be independent prognostic factors for poorer DFS in NPC patients.

In regions where NPC is prevalent, it is primarily related to EBV infection status [62]. The World Health
Table 4 Relationships between different checkpoints

\begin{tabular}{|c|c|c|c|}
\hline \multirow[t]{2}{*}{ Characteristics } & \multicolumn{3}{|c|}{ LAG-3 expression on TILs } \\
\hline & High (>14) & Low $(\leq 14)$ & $p$ value \\
\hline \multicolumn{4}{|c|}{ PD-1 expression on TILs, n (\%) } \\
\hline $\operatorname{High}(>2)$ & $79(43.4)$ & $11(6.0)$ & 0.018 \\
\hline $\operatorname{Low}(\leq 2)$ & $68(37.4)$ & $24(13.2)$ & $(1.157-5.5)$ \\
\hline \multicolumn{4}{|c|}{ PD-L1 expression on TC, n (\%) } \\
\hline $\operatorname{High}(>9)$ & $25(13.7)$ & $14(7.7)$ & 0.003 \\
\hline $\operatorname{Low}(\leq 9)$ & $122(67)$ & $21(11.6)$ & \\
\hline \multicolumn{4}{|c|}{ PD-L1 expression on TILs, n (\%) } \\
\hline $\operatorname{High}(>1 \%)$ & $130(71.4)$ & $24(13.2)$ & 0.003 \\
\hline Low $(\leq 1 \%)$ & $17(8.9)$ & $11(6.5)$ & \\
\hline \multicolumn{4}{|l|}{ CD3+TIL, n (\%) } \\
\hline High (> 215) & $105(57.7)$ & $20(11)$ & 0.101 \\
\hline $\operatorname{Low}(\leq 215)$ & $42(23.1)$ & $15(8.2)$ & \\
\hline \multicolumn{4}{|l|}{ GZMB, n (\%) } \\
\hline High (> 112) & $39(21.4)$ & $5(3.3)$ & 0.128 \\
\hline $\operatorname{Low}(\leq 112)$ & $108(58.8)$ & $30(16.5)$ & \\
\hline
\end{tabular}

Organization (WHO) has identified histological categories of NPC, among which, keratinizing squamous cell malignancy is defined as type I, differentiated non-keratinizing malignancy is defined as type II, and undifferentiated non-keratinizing malignancy is defined as type III, which is closely linked with EBV infection status [63-65]. Our findings indicate that patients who are EBV positive exhibit higher LAG-3 expression. In addition, higher expression of LAG-3 and pathological type III were identified as independent prognostic risk factors for poorer DFS. The correlation between LAG-3 and EBV status may explain the poor prognosis of NPC patients with pathological type III.

Our findings demonstrate that LAG-3 is positively related to PD-L1 expression on TCs and PD-1 expression on TILs, which is in line with the results of previous studies. One study showed that LAG-3 was closely related to PD-1 and PD-L1 expression in NSCLC [25]. LAG-3 and PD-1 can regulate immune activation and synchronously increase immunity [66]. A study investigating ovarian cancer found that LAG-3 and PD-1 can down-regulate TILs [67]. Moreover, it was shown that LAG-3 and PD-1 can synchronously regulate the behavior and anticancer response of $\mathrm{T}$ lymphocytes [68]. An in vivo study found that targeting the PD-1 or LAG-3 signaling pathways could stimulate $T$ lymphocytes, and that the combined inhibition of these pathways had a greater effect than the inhibition of each pathway alone [34]. Previous studies 
Table 5 Univariate and multivariate analysis for prediction of LAG-3 expression in all patients

\begin{tabular}{|c|c|c|c|c|c|c|}
\hline \multirow[t]{2}{*}{ Variables } & \multicolumn{3}{|c|}{ Univariate } & \multicolumn{3}{|c|}{ Multivariate } \\
\hline & OR & $95 \% \mathrm{Cl}$ & $p$ value & OR & $95 \% \mathrm{Cl}$ & $p$ value \\
\hline $\begin{array}{l}\text { Age } \\
(<60 \text { y vs. } \geq 60 y)\end{array}$ & 0.501 & $0.199-1.263$ & 0.143 & 0.604 & $0.214-1.703$ & 0.131 \\
\hline $\begin{array}{l}\text { Sex } \\
\text { (female vs. male) }\end{array}$ & 1.757 & $0.805-3.833$ & 0.157 & & & \\
\hline $\begin{array}{l}\text { Smoking status } \\
\text { (nonsmoker vs. smoker) }\end{array}$ & 0.990 & $0.372-2.636$ & 0.985 & & & \\
\hline $\begin{array}{l}\text { Pathological type } \\
\text { (I-II vs. III) }\end{array}$ & 0.630 & $0.266-1.492$ & 0.294 & & & \\
\hline $\begin{array}{l}\text { EBV status } \\
\text { (negative vs. positive) }\end{array}$ & 0.632 & $0.282-1.413$ & 0.263 & & & \\
\hline $\begin{array}{l}\text { Family history } \\
\text { (yes vs. no) }\end{array}$ & 2.123 & $0.837-5.384$ & 0.113 & 2.238 & $0.786-6.373$ & 0.131 \\
\hline $\begin{array}{l}\text { Disease stage } \\
(\text { I-II vs. III-IV) }\end{array}$ & 0.743 & $0.300-1.843$ & 0.522 & & & \\
\hline $\begin{array}{l}\text { PD-1 expression on TILs } \\
\text { (Low vs. High) }\end{array}$ & 2.535 & $1.157-5.551$ & 0.020 & 2.282 & $0.970-5.367$ & 0.059 \\
\hline $\begin{array}{l}\text { PD-L1 expression on TC } \\
\text { (Low vs. High) }\end{array}$ & 2.400 & $0.684-8.418$ & 0.113 & 0.271 & $0.105-0.695$ & 0.007 \\
\hline $\begin{array}{l}\text { PD-L1 expression on TILs } \\
\text { (Low vs. High) }\end{array}$ & 0.513 & $0.225-1.170$ & 0.005 & 3.439 & $1.280-9.237$ & 0.014 \\
\hline $\begin{array}{l}\text { CD3+TIL } \\
\text { (Low vs. High) }\end{array}$ & 1.875 & $0.878-4.006$ & 0.105 & 1.317 & $0.546-3.175$ & 0.540 \\
\hline $\begin{array}{l}\text { GZMB } \\
\text { (Low vs. High) }\end{array}$ & 2.167 & $0.785-5.979$ & 0.135 & 1.476 & $0.482-4.520$ & 0.495 \\
\hline
\end{tabular}

All the $p$ values marked in bold are less than 0.05 , which is statistically significant

LAG-3: lymphocyte activating 3; Cl: confidence interval; PD-L1: programmed death ligand 1; PD-1: programmed death 1; TIL: tumor-infiltrating lymphocyte; TC: tumor cells; GZMB: granzyme B; EBV: Epstein-Barr virus; Cl: confidence interval; OR: odds ratio

have found that LAG-3 protein expression may act synergistically with PD-1 or PD-L1 monoclonal antibodies [68-70]. Anti-LAG-3 therapy has also been shown to effectively modulate regulatory $\mathrm{T}$ lymphocytes, [71] whereas other immune checkpoints (e.g., PD-1, PD-L1, and CTLA-4 (cytotoxic T lymphocyte associated antigen-4)) have not. A total of 14 anti-cancer drugs targeting LAG-3 have been developed as of March 2021 (Table 7) (data source: https://www.clinicaltrials.gov). IMP321 was the first anti-cancer drug targeting LAG-3 to enter clinical trials. Clinical research has identified that a double blockade of immune checkpoint molecules results in enhanced clinical survival in various cancers, including renal cell carcinoma [72], melanoma [73], NSCLC [74], and small cell lung cancer [75]. It is important to note that in the reported camrelizumab antibody therapy NPC study, six out of eight patients who had formerly received ipilimumab (anti-CTLA-4) treatment exhibited a clinical response [23]. This finding indicates that a combination of immunotherapeutic strategies warrants further research.

The findings of our study indicate that the inhibition of both LAG-3 and PD-1/PD-L1 can enhance the anti-cancer response as part of a synergy. Bispecific antibodies (BsAbs) (e.g., anti-LAG3, PD-1/PD-L1) have been exploited for extensive clinical use. MGD013 is a BsAb therapy that simultaneously targets both LAG-3 and PD-1 to suppress immune checkpoint inhibition, promote $\mathrm{T}$ cell activation, and improve anti-cancer immunity. Similarly, F-star exploited a BsAb termed FS118, which simultaneously targets LAG-3 and PD-L1. In addition, numerous pharmaceutical companies in China have created LAG-3 fusion proteins, antibodies, and bispecific antibodies, which are undergoing clinical applications (Table 8) (data source: https://www.cde.org.cn/). Since LAG-3 is closely related to PD-1 and PD-L1, our study provides a novel insight and a theoretical foundation for the future development of LAG-3 and PD-1/PD-L1 bispecific antibodies to enhance the efficacy of immunotherapy for NPC.

We also observed that LAG-3 expression was associated with poor survival, which is in accordance with the results of other studies. One study indicated that high LAG-3 expression was related to worse survival in patients with NSCLC [25]. In chronic lymphocytic leukemia, LAG-3 also serves as a new predictive marker: 
A

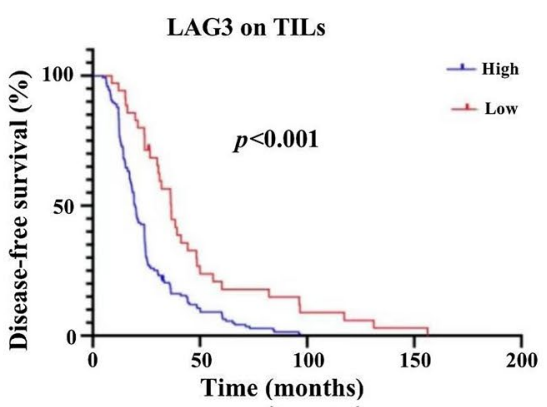

C

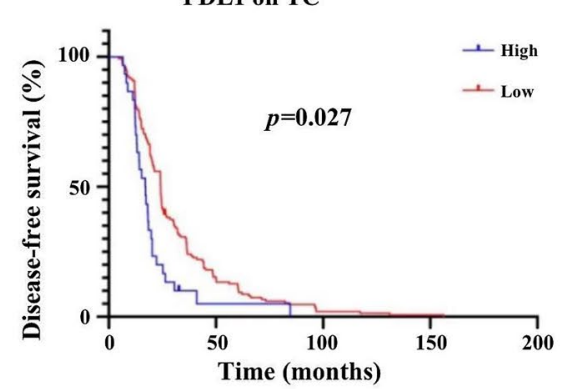

E

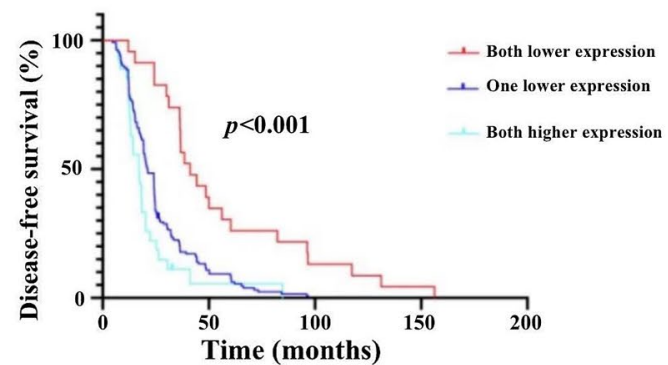

G

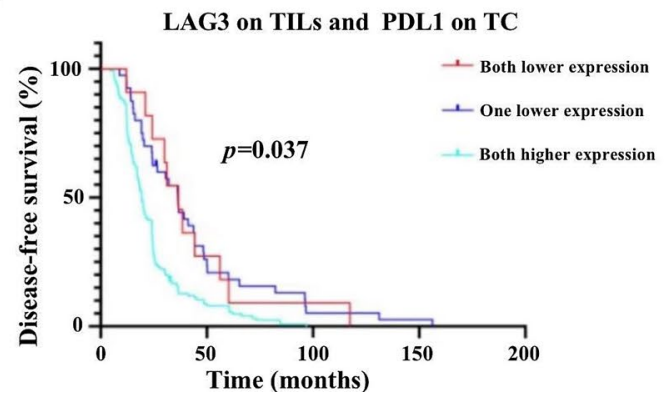

B

PD1 on TILs

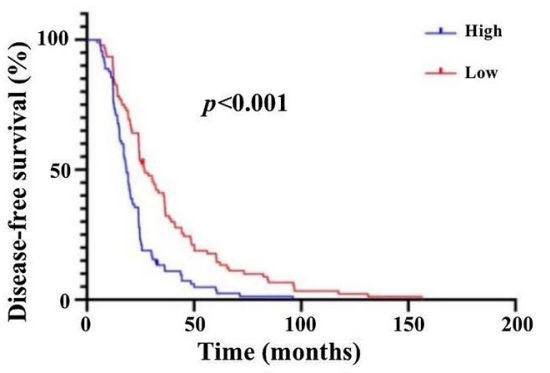

D

PDL1 on TILs

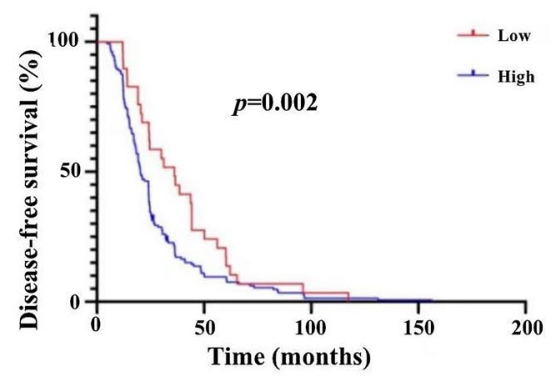

F

LAG3 and PD1 on TILs

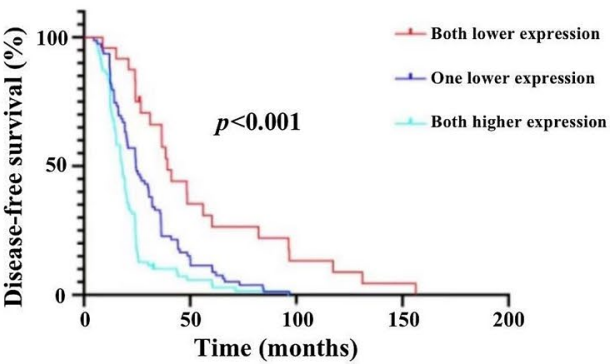

Fig. 5 The survival curves of LAG-3, PD-1, and PD-L1 on TILs, PDL1 on TCs layered by the cut-off values estimated by X-tile. A Disease-free survival (DFS) differed significantly between patients with LAG-3 expression on fewer than 14 cells and those with LAG-3 expression on more than 14 cells $(P<0.001)$. B DFS differed significantly between patients with PD-1 expression on fewer than two cells and those with PD-1 expression on more than two cells $(P<0.001)$. C DFS differed significantly between patients with PD-L1 on TCs with a score lower than nine and those with PD-L1 on TCS with a score higher than nine $(P=0.027)$. D DFS differed significantly between patients with PD-L1 expression on fewer than $1 \%$ of TILs and those with PD-L1 expression on more than 1\% of TILS $(P=0.002)$. E DFS differed significantly between patients with lower LAG-3 and PD-L1 expression on TILs and those with higher LAG-3 and PD-L1 expression on TILs $(P<0.001)$. F DFS differed significantly between patients with lower LAG-3 and PD-1 expression and those with higher LAG-3 and PD-1 expression $(P<0.001)$. G DFS differed significantly between patients with lower LAG-3 and PD-L1 expression on TCs and those with higher LAG-3 and PD-L1 expression on TCs $(P=0.037)$ 
Table 6 COX regression analysis of DFS

\begin{tabular}{|c|c|c|c|c|c|c|}
\hline \multirow[t]{2}{*}{ Variables } & \multicolumn{3}{|c|}{ Univariate } & \multicolumn{3}{|c|}{ Multivariate } \\
\hline & HR & $95 \% \mathrm{Cl}$ & $p$ value & HR & $95 \% \mathrm{Cl}$ & $p$ value \\
\hline $\begin{array}{l}\text { Age } \\
(\geq 60 \text { vs. }<60 y)\end{array}$ & 1.588 & $1.024-2.462$ & 0.039 & 1.222 & $0.779-1.916$ & 0.382 \\
\hline $\begin{array}{l}\text { Sex } \\
\text { (Female vs. Male) }\end{array}$ & 1.006 & $0.717-1.412$ & 0.972 & & & \\
\hline $\begin{array}{l}\text { Smoking status } \\
\text { (Nonsmoker vs. Smoker) }\end{array}$ & 1.049 & $0.708-1.554$ & 0.813 & & & \\
\hline $\begin{array}{l}\text { Pathological type } \\
\text { (I-II vs. III) }\end{array}$ & 0.696 & $0.495-0.977$ & 0.036 & 0.693 & $0.484-0.992$ & 0.045 \\
\hline $\begin{array}{l}\text { EBV status } \\
\text { (Negative vs. Positive) }\end{array}$ & 0.838 & $0.614-1.144$ & 0.267 & & & \\
\hline $\begin{array}{l}\text { Family history } \\
\text { (Yes vs. No) }\end{array}$ & 0.942 & $0.619-1.433$ & 0.780 & & & \\
\hline $\begin{array}{l}\text { Disease stage } \\
(\text { (III-IV vs. I-II) }\end{array}$ & 1.051 & $0.747-1.479$ & 0.773 & & & \\
\hline $\begin{array}{l}\text { LAG-3 expression on TILs } \\
\text { (Low vs. High) }\end{array}$ & 0.441 & $0.296-0.657$ & $<0.001$ & 0.434 & $0.284-0.663$ & $<0.001$ \\
\hline $\begin{array}{l}\text { PD-1 expression on TILs } \\
\text { (Low vs. High) }\end{array}$ & 0.494 & $0.363-0.671$ & $<0.001$ & 0.558 & $0.400-0.778$ & 0.001 \\
\hline $\begin{array}{l}\text { PD-L1 expression on TC } \\
\text { (Low vs. High) }\end{array}$ & 0.659 & $0.455-0.953$ & 0.027 & 0.636 & $0.432-0.937$ & 0.022 \\
\hline $\begin{array}{l}\text { PD-L1 expression on TILs } \\
\text { (Low vs. High) }\end{array}$ & 0.678 & $0.452-1.017$ & 0.002 & 1.050 & $0.667-1.654$ & 0.832 \\
\hline $\begin{array}{l}\text { CD3+TIL } \\
\text { (Low vs. High) }\end{array}$ & 1.179 & $0.731-1.900$ & 0.499 & & & \\
\hline $\begin{array}{l}\text { GZMB } \\
\text { (Low vs. High) }\end{array}$ & 0.661 & $0.467-0.936$ & 0.063 & 1.119 & $0.757-1.653$ & 0.574 \\
\hline
\end{tabular}

All the $p$ values marked in bold are less than 0.05 , which is statistically significant

LAG-3: lymphocyte activating 3; PD-L1: programmed death ligand 1; PD-1: programmed death 1; GZMB: granzyme B; TL: tumor-infiltrating lymphocyte; TC: tumor cells; DFS: disease-free survival; HR: hazard ratio; Cl: confidence interval

higher expression of LAG-3 was associated with shorter survival [76]. Yet, in contrast, several studies have found that high LAG-3 was correlated with better survival in patients with gastric carcinoma [40] and breast carcinoma [41]. Thus, LAG-3 represents a potential immune checkpoint target. Despite the numerous ongoing antiLAG-3 studies, the literature related to LAG-3 and NPC remains insufficient. Consequently, it is necessary to further explore the prognostic value of LAG-3 in NPC. The findings of our present study indicate that LAG-3 may participate in the tumor immune escape of NPC as an interpretation of the observed poor survival in NPC patients. In addition, the association of LAG-3 and GZMB, and CD3+TIL expression was also analyzed. However, no correlation between LAG-3 and GZMB or CD3+ TIL expression was found. A previous study indicated that lower CD3+ TIL infiltration was related to a worse DFS in patients with NPC [47] and HCC [77], which is inconsistent with our findings. Our finding that CD3 was unrelated to NPC prognosis may be attributed to our comparatively small case size. Further investigation with a larger sample size and an independent cohort of patients is required.

There are some limitations of our study. First, this was a retrospective study, and we only collected information from one institute, and the overall survival data was insufficient for rigorous analysis. Secondly, since previous related reports have not identified the optimal cut-off value for LAG-3, X-tile was used to determine the cut-off values for predicting DFS. Finally, the sample size of this population was small. Further research involving a larger number of NPC patients is required.

\section{Conclusions}

Immune checkpoints play a critical role in immune regulation. Yet, the synergistic effects between multiple immune targets remains unknown. CTLA-4, PD-1, and PD-L1 antibody immunotherapy have demonstrated significant effectiveness for the treatment of some cancers. LAG-3 represents another potential therapeutic target whose synergistic effect requires further investigation. In our present study, we found that LAG-3 was closely associated with PD-1/PD-L1 expression. Positive LAG-3 
Table 7 Clinical trials targeting LAG-3 expression as of March 2021

\begin{tabular}{|c|c|c|c|c|}
\hline Antibody name & Targets & Clinical studies & Phase & Conditions \\
\hline \multirow[t]{8}{*}{ IMP321 } & LAG-3 Fusion Protein & NCT00732082 & Phase I & Pancreatic neoplasms \\
\hline & & NCT03252938 & Phase I & Solid tumors \\
\hline & & NCT00351949 & Phase I & Stage IV renal cell Carcinoma \\
\hline & & NCT03625323 & Phase II & NSCLC, head and neck squamous cell carcinoma (HNSCC) \\
\hline & & NCT04252768 & Phase I & Metastatic breast cancer \\
\hline & & NCT00349934 & Phase I & Metastatic breast cancer \\
\hline & & NCT02614833 & Phase II & Adenocarcinoma breast \\
\hline & & NCT04811027 & Phase II & HNSCC \\
\hline \multirow[t]{21}{*}{ Relatlimab } & LAG-3 & NCT04080804 & Phase II & HNSCC \\
\hline & & NCT01968109 & Phase I/Ila & Neoplasms \\
\hline & & NCT02061761 & Phase I/Ila & Hematologic neoplasms \\
\hline & & NCT03610711 & Phase II & Gastroesophageal cancer \\
\hline & & NCT02658981 & Phase I & Glioblastoma \\
\hline & & NCT04150965 & Phase $1 / \|$ & Multiple myeloma \\
\hline & & NCT03044613 & Phase lb & Gastric cancer, Esophageal cancer, gastroesophageal cancer \\
\hline & & NCT04611126 & Phase I & Metastatic ovarian cancer, metastatic fallopian tube cancer, peritoneal cancer \\
\hline & & NCT03623854 & Phase II & Chordoma \\
\hline & & NCT03459222 & Phase $\mid / I I$ & Advanced cancer \\
\hline & & NCT02966548 & Phase I & Cancer \\
\hline & & NCT03662659 & Phase II & Gastric cancer, cancer of the stomach, esophagogastric Junction \\
\hline & & NCT03743766 & Phase II & Melanoma \\
\hline & & NCT04326257 & Phase II & Squamous cell carcinoma of the head and neck \\
\hline & & NCT04658147 & Phase I & Hepatocellular carcinoma \\
\hline & & NCT03607890 & Phase II & Cancer \\
\hline & & NCT04567615 & Phase II & Hepatocellular carcinoma \\
\hline & & NCT02519322 & Phase II & Melanoma \\
\hline & & NCT02060188 & Phase II & Microsatellite unstable colorectal cancer \\
\hline & & NCT03493932 & Phase I & Glioblastoma \\
\hline & & NCT02488759 & Phase $1 / \|$ & Advanced cancer \\
\hline \multirow[t]{3}{*}{ Sym022 } & LAG-3 & NCT03489369 & Phase I & Metastatic cancer \\
\hline & & NCT04641871 & Phase I & Metastatic cancer \\
\hline & & NCT03311412 & Phase I & Metastatic cancer \\
\hline \multirow[t]{2}{*}{ RO7247669 } & PD-1 x LAG-3 & NCT04140500 & Phase I & Solid tumors \\
\hline & & NCT04785820 & Phase II & $\begin{array}{l}\text { Advanced or metastatic esophageal } \\
\text { Squamous cell carcinoma }\end{array}$ \\
\hline REGN3767 & LAG-3 & NCT03005782 & Phase I & Malignancies \\
\hline TSR-033 & LAG-3 & NCT03250832 & Phase I & Neoplasms \\
\hline EMB-02 & PD-1 x LAG-3 & NCT04618393 & Phase $\mid / \|$ & Advanced solid tumors \\
\hline \multirow[t]{4}{*}{ MGD013 } & PD-1 x LAG-3 & NCT03219268 & Phase I & Advanced solid tumors \\
\hline & & NCT04082364 & Phase II/III & Gastric cancer \\
\hline & & NCT04634825 & Phase II & Colorectal cancer \\
\hline & & NCT04129320 & Phase II/III & Head and neck cancer \\
\hline FS118 & $P D-L 1 \times L A G-3$ & NCT03440437 & Phase $1 / 11$ & Advanced cancer \\
\hline INCAGN02385 & LAG-3 & NCT04370704 & Phase I/II & Melanoma \\
\hline TSR-033 & LAG-3 & NCT02817633 & Phase I & Neoplasms \\
\hline \multirow[t]{3}{*}{ LAG525 } & $L A G-3$ & NCT03365791 & Phase II & Advanced solid tumors, diffuse large B cell lymphoma \\
\hline & & NCT03742349 & Phase I & Triple negative breast cancer \\
\hline & & NCT02460224 & Phase $\mathrm{I} / \mathrm{II}$ & Advanced solid tumors \\
\hline $\mathrm{XmAb}-22841$ & CTLA-4 $\times$ LAG-3 & NCT03849469 & Phase I & Advanced solid tumors \\
\hline EOC202 & LAG-3 fusion protein & NCT03600090 & Phase I & Advanced solid tumors \\
\hline
\end{tabular}


Table 7 (continued)

NSCLC: non-small cell lung cancer; HNSCC: head and neck squamous cell carcinoma; LAG-3: lymphocyte activating 3; PD-L1: programmed death ligand 1; PD-1: programmed death 1; CTLA-4: cytotoxic T-lymphocyte antigen 4

Table 8 Clinical applications as of March 2021 for bispecific antibodies targeting LAG-3 expression

\begin{tabular}{llll}
\hline Antibody name & Targets & $\begin{array}{l}\text { Clinical application } \\
\text { acceptance number }\end{array}$ & Date \\
\hline HLX26 & LAG-3 & CXSL2100041 & 2021-02-03 \\
IBI323 & PD-L1 $\times$ LAG-3 & CXSL2000242 & 2020-08-25 \\
EMB-02 & PD-1 $\times$ LAG-3 & CXSL2100047 & 2020-05-23 \\
DNV3 & LAG-3 & CXSL2000121 & $2020-05-22$ \\
KL-A289 & LAG-3 & CXSL2000108 & $2019-11-16$ \\
MGD013 & PD-1 $\times$ LAG-3 & JXSL1900114 & $2019-08-23$ \\
SHR-1802 & LAG-3 & CXSL1900090 & $2019-05-27$ \\
LBL-007 & LAG-3 & JXSL1900040 & $2019-04-26$ \\
IBI110 & LAG-3 & CXSL1900040 & $2019-04-26$ \\
EOC202 & LAG-3 & CTR20180185 & $2018-06-25$ \\
\hline
\end{tabular}

LAG-3: lymphocyte activating 3; PD-L1: programmed death ligand 1; PD-1: programmed death 1

expression or the expression of both LAG-3 and PD-L1 has been associated with early cancer relapse. Male and EBV-positive patients were associated with higher LAG-3 expression in our study. Lower LAG-3, PD-1, and PD-L1 expression were also associated with a longer DFS. Importantly, high LAG-3, PD-1, and PD-L1 expression on TCs, and Pathological type III were confirmed to be independent risk factors for poorer DFS in NPC patients. Based on the findings of our study and observations supporting its potential synergistic function when administered in conjunction with anti-PD-1/PD-L1, the inhibition LAG-3 is a promising inhibitory receptor and anti-LAG3 will likely play a critical role in anti-neoplastic therapy. Our study provides a theoretical foundation for the exploitation of BsAbs against LAG-3 or PD-1 on TILs, and PD-L1 on TCs. However, to date, there has been minimal research into the synergistic interactions between LAG-3 and other promising immune checkpoint molecules, such as $\mathrm{T}$ cell immunoglobulin-3. Future investigations are warranted.

\footnotetext{
Abbreviations

NPC: Nasopharyngeal carcinoma; PD-1: Programmed cell death-1; PD-L1: Programmed cell death ligand-1; Th1:T helper; TCs: Tumor cells; TILs: Tumorinfiltrating lymphocytes; MSI: Microsatellite instability; TMB: Tumor mutational burden; PFS: Progression-free survival; LAG-3: Lymphocyte activating gene 3; NSCLC: Non-small cell lung cancer; TME: Tumor microenvironment; NK: Natural killer; CTL: Cytotoxic T lymphocyte; GZMB: Granzyme B; OS: Overall survival; HCC: Hepatocellular carcinoma; MHC: Major histocompatibility complex; HRP: Horseradish peroxidase; DAB, 3: 3'-Diaminobenzidine; PBS: Phosphate-buffered saline; SYSUCC: Sun Yat-sen University Cancer Center; TNM: Tumor node metastasis; AJCC: American Joint Committee on Cancer; EBV: Epstein-Barr virus; TMA: Tissue microarray; IHC: Immunohistochemical;
}

HE: Hematoxylin-eosin; WHO: World Health Organization; CTLA-4: Cytotoxic T lymphocyte associated antigen-4; BsAb: Bispecific antibodies; $\mathrm{Cl}$ : Confidence interval; OR: Odds ratio; HR: Hazard ratio; DFS: Disease-free survival.

\section{Supplementary Information}

The online version contains supplementary material available at https://doi. org/10.1186/s12935-021-02162-w.

Additional file 1: Figure S1. Hematoxylin-eosin (HE) staining of all 15 NPC cell lines $(\times 20)$. Scale bars: $50 \mu \mathrm{m}$.

Acknowledgements

We thank all the patients for participating in this retrospective study.

\section{Authors' contributions}

FL, JC and FL contributed equally to this article and should be considered cofirst authors. Study concept and design: FL, JC and FL. Analysis and interpretation of data: $F L, J C, F L, K Z, W M, Y H, L Z$ and HZ. Clinical information collection: $\mathrm{FL}, J \mathrm{C}, \mathrm{FL}, \mathrm{KZ}, \mathrm{WM}, \mathrm{YH}, \mathrm{LZ}$ and $\mathrm{HZ}$. The dataset used for this study is available upon reasonable request. All authors were involved in the drafting, reviewing, and approval of the report and the decision to submit for publication. All authors read and approved the final manuscript.

\section{Funding}

This study was supported by the 5010 Clinical Research Foundation of Sun Yat-sen University (2016001); the Natural Science Foundation of Guangdong Province of China (2018A0303130243, 2020A1515011464); the National Natural Science Foundation Project of China (82073396, 81872201, 81872499, and 82002628); the Science and Technology Program of Guangdong Province; China (2017B020227001); the Medical Scientific Research Foundation of Guangdong Province; China (C2018062); and the China Postdoctoral Science Foundation (2019M660227).

\section{Availability of data and materials}

The datasets used and analyzed in this study are available from the corresponding author upon reasonable request. The authenticity of this article has been validated by uploading the key raw data onto the Research Data Deposit public platform (https://www.researchdata.org.cn), with the approval RDD number as RDDA2021002093.

\section{Declarations}

Ethics approval and consent to participate

This study was approved by the local ethics committee of Sun Yat-sen University Cancer Center and all study subjects provided written informed consent.

Consent for publication

Not applicable.

\section{Competing interests}

All the authors declare that they have no competing interests.

\section{Author details}

${ }^{1}$ Department of Experimental Research, State Key Laboratory of Oncology in South China, Collaborative Innovation Center for Cancer Medicine, Sun Yat-Sen University Cancer Center, Guangzhou, China. ${ }^{2}$ Department of Medical Oncology, State Key Laboratory of Oncology in South China, Collaborative Innovation Center for Cancer Medicine, Sun Yat-Sen University Cancer Center, 651 Dongfeng Road East, Guangzhou 510060, Guangdong, China. ${ }^{3}$ Department of Intensive Care Unit, State Key Laboratory of Oncology in South China, Collaborative Innovation Center for Cancer Medicine, Sun Yat-Sen University Cancer Center, Guangzhou, China. ${ }^{4}$ Department of Clinical Research, State 
Key Laboratory of Oncology in South China, Collaborative Innovation Center for Cancer Medicine, Sun Yat-Sen University Cancer Center, 651 Dongfeng Road East, Guangzhou 510060, Guangdong, China.

Received: 18 May 2021 Accepted: 18 August 2021 Published online: 28 August 2021

\section{References}

1. Yu MC, Yuan JM. Epidemiology of nasopharyngeal carcinoma. Semin Cancer Biol. 2002;12(6):421-9.

2. Henderson BE, Louie E, SooHoo Jing J, Buell P, Gardner MB. Risk factors associated with nasopharyngeal carcinoma. N Engl J Med. 1976;295(20):1101-6.

3. Lee AW, Ng WT, Chan LL, Hung WM, Chan CC, Sze HC, Chan OS, Chang AT, Yeung RM. Evolution of treatment for nasopharyngeal cancer-success and setback in the intensity-modulated radiotherapy era. Radiother Oncol. 2014;110(3):377-84.

4. Zhang B, Mo Z, Du W, Wang Y, Liu L, Wei Y. Intensity-modulated radiation therapy versus 2D-RT or 3D-CRT for the treatment of nasopharyngeal carcinoma: a systematic review and meta-analysis. Oral Oncol. 2015;51(11):1041-6

5. Lee AW, Ma BB, Ng WT, Chan AT. Management of nasopharyngeal carcinoma: current practice and future perspective. J Clin Oncol. 2015;33(29):3356-64.

6. Ma BBY, Lim WT, Goh BC, Hui EP, Lo KW, Pettinger A, Foster NR, Riess JW, Agulnik M, Chang AYC, et al. Antitumor Activity of nivolumab in recurrent and metastatic nasopharyngeal carcinoma: an International, Multicenter Study of the Mayo Clinic Phase 2 Consortium (NCl-9742). J Clin Oncol. 2018:36(14):1412-8.

7. Turley SJ, Cremasco V, Astarita JL. Immunological hallmarks of stromal cells in the tumour microenvironment. Nat Rev Immunol. 2015;15(11):669-82.

8. Chen L, Han X. Anti-PD-1/PD-L1 therapy of human cancer: past, present, and future. J Clin Invest. 2015;125(9):3384-91.

9. Hsu C, Lee SH, Ejadi S, Even C, Cohen RB, Le Tourneau C, Mehnert JM, Algazi A, van Brummelen EMJ, Saraf S, et al. Safety and antitumor activity of pembrolizumab in patients with programmed death-ligand 1-positive nasopharyngeal carcinoma: results of the KEYNOTE-028 Study. J Clin Oncol. 2017;35(36):4050-6.

10. Chen DS, Irving BA, Hodi FS. Molecular pathways: next-generation immunotherapy-inhibiting programmed death-ligand 1 and programmed death-1. Clin Cancer Res. 2012;18(24):6580-7.

11. Okazaki T, Honjo T. PD-1 and PD-1 ligands: from discovery to clinical application. Int Immunol. 2007;19(7):813-24.

12. Keir ME, Butte MJ, Freeman GJ, Sharpe AH. PD-1 and its ligands in tolerance and immunity. Annu Rev Immunol. 2008;26:677-704.

13. Billon E, Finetti P, Bertucci A, Niccoli P, Birnbaum D, Mamessier E, Bertucc F. PDL1 expression is associated with longer postoperative, survival in adrenocortical carcinoma. Oncoimmunology. 2019;8(11):e1655362.

14. Tumeh PC, Harview CL, Yearley JH, Shintaku IP, Taylor EJ, Robert L, Chmielowski B, Spasic M, Henry G, Ciobanu V, et al. PD-1 blockade induces responses by inhibiting adaptive immune resistance. Nature. 2014;515(7528):568-71.

15. Lee N, Zakka LR, Mihm MC Jr, Schatton T. Tumour-infiltrating lymphocytes in melanoma prognosis and cancer immunotherapy. Pathology. 2016;48(2):177-87.

16. Rodriquenz MG, Roviello G, D'Angelo A, Lavacchi D, Roviello F, Polom K. MSI and EBV Positive gastric cancer's subgroups and their link with novel immunotherapy. J Clin Med. 2020. 2020;9(5): 1427.

17. Schalper KA, Kaftan E, Herbst RS. Predictive biomarkers for PD-1 axis therapies: the hidden treasure or a call for research. Clin Cancer Res. 2016;22(9):2102-4.

18. Chan OS, Kowanetz M, Ng WT, Koeppen H, Chan LK, Yeung RM, Wu H, Amler L, Mancao C. Characterization of PD-L1 expression and immune cell infiltration in nasopharyngeal cancer. Oral Oncol. 2017;67:52-60.

19. Huang ZL, Liu S, Wang GN, Zheng SH, Ding SR, Tao YL, Chen C, Liu SR, Yang $\mathrm{X}$, Chang $\mathrm{H}$, et al. The prognostic significance of PD-L1 and PD-1 expression in patients with nasopharyngeal carcinoma: a systematic review and meta-analysis. Cancer Cell Int. 2019;19:141.
20. Zhang J, Fang W, Qin T, Yang Y, Hong S, Liang W, Ma Y, Zhao H, Huang Y, Xue C, et al. Co-expression of PD-1 and PD-L1 predicts poor outcome in nasopharyngeal carcinoma. Med Oncol. 2015;32(3):86

21. Zhang Y, Kang S, Shen J, He J, Jiang L, Wang W, Guo Z, Peng G, Chen G, $\mathrm{He}$, et al. Prognostic significance of programmed cell death 1 (PD-1) or PD-1 ligand 1 (PD-L1) expression in epithelial-originated cancer: a metaanalysis. Medicine. 2015;94(6):e515.

22. Zhu Q, Cai MY, Chen CL, Hu H, Lin HX, Li M, Weng DS, Zhao JJ, Guo L, Xia JC. Tumor cells PD-L1 expression as a favorable prognosis factor in nasopharyngeal carcinoma patients with pre-existing intratumor-infiltrating lymphocytes. Oncoimmunology. 2017;6(5):e1312240.

23. Fang W, Yang Y, Ma Y, Hong S, Lin L, He X, Xiong J, Li P, Zhao H, Huang Y, et al. Camrelizumab (SHR-1210) alone or in combination with gemcitabine plus cisplatin for nasopharyngeal carcinoma: results from two single-arm, phase 1 trials. Lancet Oncol. 2018;19(10):1338-50.

24. Prawira A, Oosting SF, Chen TW, Delos Santos KA, Saluja R, Wang L, Siu LL, Chan KKW, Hansen AR. Systemic therapies for recurrent or metastatic nasopharyngeal carcinoma: a systematic review. Br J Cancer. 2017;117(12):1743-52.

25. He Y, Yu H, Rozeboom L, Rivard CJ, Ellison K, Dziadziuszko R, Suda K, Ren S, Wu C, Hou L, et al. LAG-3 protein expression in non-small cell lung cancer and its relationship with PD-1/PD-L1 and tumor-infiltrating lymphocytes. J Thorac Oncol. 2017;12(5):814-23.

26. Triebel F, Jitsukawa S, Baixeras E, Roman-Roman S, Genevee C, ViegasPequignot E, Hercend T. LAG-3, a novel lymphocyte activation gene closely related to CD4. J Exp Med. 1990;171(5):1393-405.

27. Kisielow M, Kisielow J, Capoferri-Sollami G, Karjalainen K. Expression of lymphocyte activation gene 3 (LAG-3) on B cells is induced by T cells. Eur J Immunol. 2005;35(7):2081-8.

28. Grosso JF, Kelleher CC, Harris TJ, Maris CH, Hipkiss EL, De Marzo A, Anders $R$, Netto G, Getnet D, Bruno TC, et al. LAG-3 regulates CD8+ T cell accumulation and effector function in murine self- and tumor-tolerance systems. J Clin Invest. 2007;117(11):3383-92.

29. Andreae S, Piras F, Burdin N, Triebel F. Maturation and activation of dendritic cells induced by lymphocyte activation gene-3 (CD223). J Immunol. 2002;168(8):3874-80.

30. Workman CJ, Wang Y, El Kasmi KC, Pardoll DM, Murray PJ, Drake CG, Vignali DA. LAG-3 regulates plasmacytoid dendritic cell homeostasis. J Immunol. 2009;182(4):1885-91.

31. Huard B, Mastrangeli R, Prigent P, Bruniquel D, Donini S, El-Tayar N, Maigret B, Dreano M, Triebel F. Characterization of the major histocompatibility complex class II binding site on LAG-3 protein. Proc Natl Acad Sci U S A. 1997;94(11):5744-9.

32. Huard B, Prigent $P$, Tournier M, Bruniquel D, Triebel F. CD4/major histocompatibility complex class II interaction analyzed with CD4- and lymphocyte activation gene-3 (LAG-3)-Ig fusion proteins. Eur J Immunol. 1995;25(9):2718-21.

33. Weber S, Karjalainen K. Mouse CD4 binds MHC class II with extremely low affinity. Int Immunol. 1993;5(6):695-8.

34. Blackburn SD, Shin H, Haining WN, Zou T, Workman CJ, Polley A, Betts MR, Freeman GJ, Vignali DA, Wherry EJ. Coregulation of CD8+T cell exhaustion by multiple inhibitory receptors during chronic viral infection. Nat Immunol. 2009;10(1):29-37.

35. Cappello P, Triebel F, lezzi M, Caorsi C, Quaglino E, Lollini PL, Amici A, Di Carlo E, Musiani P, Giovarelli M, et al. LAG-3 enables DNA vaccination to persistently prevent mammary carcinogenesis in HER-2/neu transgenic BALB/c mice. Cancer Res. 2003;63(10):2518-25.

36. Chun T, Byun HJ, Chung HY, Chung YH. The effect of soluble LAG-3 (CD223) treatment in fetal thymic organ culture. Biotechnol Lett. 2004;26(17):1371-7.

37. Grosso JF, Goldberg MV, Getnet D, Bruno TC, Yen HR, Pyle KJ, Hipkiss E, Vignali DA, Pardoll DM, Drake CG. Functionally distinct LAG-3 and PD-1 subsets on activated and chronically stimulated CD8 T cells. J Immunol. 2009;182(11):6659-69.

38. Huang CT, Workman CJ, Flies D, Pan X, Marson AL, Zhou G, Hipkiss EL, Ravi S, Kowalski J, Levitsky HI, et al. Role of LAG-3 in regulatory $T$ cells. Immunity. 2004;21(4):503-13.

39. Johnson DB, Nixon MJ, Wang Y, Wang DY, Castellanos E, Estrada MV, Ericsson-Gonzalez PI, Cote CH, Salgado R, Sanchez V, et al. Tumor-specific MHC-II expression drives a unique pattern of resistance to immunotherapy via LAG-3/FCRL6 engagement. JCI Insight. 2018;3(24):e120360. 
40. Ohmura H, Yamaguchi K, Hanamura F, Ito M, Makiyama A, Uchino K, Shimokawa H, Tamura S, Esaki T, Mitsugi K, et al. OX40 and LAG3 are associated with better prognosis in advanced gastric cancer patients treated with anti-programmed death-1 antibody. Br J Cancer. 2020;122(10):1507-17.

41. Sidaway P. Breast cancer: LAG3 expression indicates favourable outcomes. Nat Rev Clin Oncol. 2017;14(12):712.

42. Gameiro SF, Ghasemi F, Barrett JW, Koropatnick J, Nichols AC, Mymryk JS, Maleki Vareki S. Treatment-naïve HPV+ head and neck cancers display a T-cell-inflamed phenotype distinct from their HPV-counterparts that has implications for immunotherapy. Oncoimmunology. 2018;7(10):e1498439.

43. van der Zwan A, Bi K, Norwitz ER, Crespo ÂC, Claas FHJ, Strominger JL, Tilburgs T. Mixed signature of activation and dysfunction allows human decidual CD8(+) T cells to provide both tolerance and immunity. Proc Natl Acad Sci USA. 2018;115(2):385-90.

44. Zhang Q, Chikina M, Szymczak-Workman AL, Horne W, Kolls JK, Vignali KM, Normolle D, Bettini M, Workman CJ, Vignali DAA. LAG3 limits regulatory $T$ cell proliferation and function in autoimmune diabetes. Sci Immunol. 2017;2(9):eaah4569.

45. Dumic J, Dabelic S, Flögel M. Galectin-3: an open-ended story. Biochim Biophys Acta. 2006;1760(4):616-35.

46. Hsu MC, Hsiao JR, Chang KC, Wu YH, Su IJ, Jin YT, Chang Y. Increase of programmed death-1-expressing intratumoral CD8T cells predicts a poor prognosis for nasopharyngeal carcinoma. Mod Pathol. 2010;23(10):1393-403.

47. Al-Rajhi N, Soudy H, Ahmed SA, Elhassan T, Mohammed SF, Khoja HA, Ghebeh H. CD3+T-lymphocyte infiltration is an independent prognostic factor for advanced nasopharyngeal carcinoma. BMC Cancer 2020;20(1):240.

48. Mhaidat NM, Al-azzam SI, Alzoubi KH, Khabour OF, Gharaibeh BF. Granzyme B gene polymorphisms, colorectal cancer risk, and metastasis. J Cancer Res Ther. 2014;10(3):587-90.

49. Wowk ME, Trapani JA. Cytotoxic activity of the lymphocyte toxin granzyme B. Microbes Infect. 2004;6(8):752-8.

50. Smyth MJ, McGuire MJ, Thia KY. Expression of recombinant human granzyme B. A processing and activation role for dipeptidyl peptidase I. J Immunol. 1995;154(12):6299-305.

51. Ding W, Xu X, Qian Y, Xue W, Wang Y, Du J, Jin L, Tan Y. Prognostic value of tumor-infiltrating lymphocytes in hepatocellular carcinoma: a metaanalysis. Medicine. 2018;97(50):e13301.

52. Salama P, Phillips M, Platell C, lacopetta B. Low expression of granzyme B in colorectal cancer is associated with signs of early metastastic invasion. Histopathology. 2011;59(2):207-15.

53. Wang Y, Dong T, Xuan Q, Zhao H, Qin L, Zhang Q. Lymphocyte-activation gene-3 expression and prognostic value in neoadjuvant-treated triplenegative breast cancer. J Breast Cancer. 2018;21(2):124-33.

54. Noh BJ, Kwak JY, Eom DW. Immune classification for the PD-L1 expression and tumour-infiltrating lymphocytes in colorectal adenocarcinoma. BMC Cancer. 2020;20(1):58.

55. Zheng H, Zhou C, Lu X, Liu Q, Liu M, Chen G, Chen W, Wang S, Qiu Y. DJ-1 promotes survival of human colon cancer cells under hypoxia by modulating HIF-1a expression through the PI3K-AKT pathway. Cancer Manag Res. 2018;10:4615-29.

56. Camp RL, Dolled-Filhart M, Rimm DL. X-tile: a new bio-informatics tool for biomarker assessment and outcome-based cut-point optimization. Clin Cancer Res. 2004;10(21):7252-9.

57. He Y, Rivard CJ, Rozeboom L, Yu H, Ellison K, Kowalewski A, Zhou C, Hirsch FR. Lymphocyte-activation gene-3, an important immune checkpoint in cancer. Cancer Sci. 2016;107(9):1193-7.

58. Gandhi MK, Lambley E, Duraiswamy J, Dua U, Smith C, Elliott S, Gill D, Marlton P, Seymour J, Khanna R. Expression of LAG-3 by tumor-infiltrating lymphocytes is coincident with the suppression of latent membrane antigen-specific CD8+ T-cell function in Hodgkin lymphoma patients. Blood. 2006;108(7):2280-9.

59. Martin MP, Borecki IB, Zhang Z, Nguyen L, Ma D, Gao X, Qi Y, Carrington M, Rader JS. HLA-Cw group 1 ligands for KIR increase susceptibility to invasive cervical cancer. Immunogenetics. 2010;62(11-12):761-5.

60. Burova E, Hermann A, Dai J, Ullman E, Halasz G, Potocky T, Hong S, Liu M, Allbritton O, Woodruff A, et al. Preclinical development of the anti-LAG-3 antibody REGN3767: characterization and activity in combination with the anti-PD-1 antibody cemiplimab in human PD-1xLAG-3-knockin mice. Mol Cancer Ther. 2019;18(11):2051-62.

61. Ghosh S, Sharma G, Travers J, Kumar S, Choi J, Jun HT, Kehry M, Ramaswamy S, Jenkins D. TSR-033, a novel therapeutic antibody targeting LAG-3, enhances T-cell function and the activity of PD-1 blockade in vitro and in vivo. Mol Cancer Ther. 2019;18(3):632-41.

62. Wan XX, Yi H, Qu JQ, He QY, Xiao ZQ. Integrated analysis of the differential cellular and EBV miRNA expression profiles in microdissected nasopharyngeal carcinoma and non-cancerous nasopharyngeal tissues. Oncol Rep. 2015;34(5):2585-601.

63. Müller E, Beleites E. The basaloid squamous cell carcinoma of the nasopharynx. Rhinology. 2000;38(4):208-11.

64. Roy C, Choudhury KB, Basu S. Basaloid squamous cell carcinoma of nasopharynx: an extremely rare variety of tumour of nasopharynx. J Indian Med Assoc. 2011;109(5):343-4.

65. Wei WI, Sham JS. Nasopharyngeal carcinoma. Lancet. 2005;365(9476):2041-54.

66. Okazaki T, Okazaki IM, Wang J, Sugiura D, Nakaki F, Yoshida T, Kato Y, Fagarasan S, Muramatsu M, Eto T, et al. PD-1 and LAG-3 inhibitory coreceptors act synergistically to prevent autoimmunity in mice. J Exp Med. 2011;208(2):395-407.

67. Matsuzaki J, Gnjatic S, Mhawech-Fauceglia P, Beck A, Miller A, Tsuji T, Eppolito C, Qian F, Lele S, Shrikant P, et al. Tumor-infiltrating NY-ESO1-specific CD8 + T cells are negatively regulated by LAG-3 and PD-1 in human ovarian cancer. Proc Natl Acad Sci U S A. 2010;107(17):7875-80.

68. Woo SR, Turnis ME, Goldberg MV, Bankoti J, Selby M, Nirschl CJ, Bettini ML, Gravano DM, Vogel P, Liu CL, et al. Immune inhibitory molecules LAG-3 and PD-1 synergistically regulate T-cell function to promote tumoral immune escape. Cancer Res. 2012;72(4):917-27.

69. Lucas CL, Workman CJ, Beyaz S, LoCascio S, Zhao G, Vignali DA, Sykes M. LAG-3, TGF- $\beta$, and cell-intrinsic PD-1 inhibitory pathways contribute to CD8 but not CD4 T-cell tolerance induced by allogeneic BMT with antiCD40L. Blood. 2011;117(20):5532-40.

70. Richter K, Agnellini P, Oxenius A. On the role of the inhibitory receptor LAG-3 in acute and chronic LCMV infection. Int Immunol. 2010;22(1):13-23.

71. Gagliani N, Magnani CF, Huber S, Gianolini ME, Pala M, Licona-Limon P, Guo B, Herbert DR, Bulfone A, Trentini F, et al. Coexpression of CD49b and LAG-3 identifies human and mouse T regulatory type 1 cells. Nat Med. 2013;19(6):739-46.

72. Motzer RJ, Tannir NM, McDermott DF, Aren Frontera O, Melichar B, Choueiri TK, Plimack ER, Barthelemy P, Porta C, George S, et al. Nivolumab plus Ipilimumab versus sunitinib in advanced renal-cell carcinoma. $\mathrm{N}$ Engl J Med. 2018;378(14):1277-90.

73. Larkin J, Chiarion-Sileni V, Gonzalez R, Grob JJ, Cowey CL, Lao CD, Schadendorf D, Dummer R, Smylie M, Rutkowski P, et al. Combined nivolumab and ipilimumab or monotherapy in untreated melanoma. N Engl J Med. 2015;373(1):23-34.

74. Hellmann MD, Ciuleanu TE, Pluzanski A, Lee JS, Otterson GA, AudigierValette C, Minenza E, Linardou H, Burgers S, Salman P, et al. Nivolumab plus Ipilimumab in lung cancer with a high tumor mutational burden. N Engl J Med. 2018;378(22):2093-104.

75. Antonia SJ, López-Martin JA, Bendell J, Ott PA, Taylor M, Eder JP, Jäger D, Pietanza MC, Le DT, de Braud F, et al. Nivolumab alone and nivolumab plus ipilimumab in recurrent small-cell lung cancer (CheckMate 032): a multicentre, open-label, phase 1/2 trial. Lancet Oncol. 2016;17(7):883-95.

76. Kotaskova J, Tichy B, Trbusek M, Francova HS, Kabathova J, Malcikova J, Doubek M, Brychtova Y, Mayer J, Pospisilova S. High expression of lymphocyte-activation gene 3 (LAG3) in chronic lymphocytic leukemia cells is associated with unmutated immunoglobulin variable heavy chain region (IGHV) gene and reduced treatment-free survival. J Mol Diagn. 2010;12(3):328-34

77. Gabrielson A, Wu Y, Wang H, Jiang J, Kallakury B, Gatalica Z, Reddy S, Kleiner D, Fishbein T, Johnson L, et al. Intratumoral CD3 and CD8 T-cell densities associated with relapse-free survival in HCC. Cancer Immunol Res. 2016;4(5):419-30.

\section{Publisher's Note}

Springer Nature remains neutral with regard to jurisdictional claims in published maps and institutional affiliations. 